\title{
TAT-mediated si-hWAPL inhibits the invasion and metastasis of cervical cancer stem cells
}

\author{
PIJUN GONG $^{1 *}$, CHUNYAN HU $^{2 *}$, XI ZHOU $^{3}$, RENXIAO WANG $^{3}$ and ZHAO DUAN ${ }^{1}$ \\ ${ }^{1}$ Department of Obstetrics and Gynecology, The Second Affiliated Hospital of Xi'an Jiaotong University, \\ Xi'an, Shaanxi 710004; ${ }^{2}$ Department of Gynecology, Northwest Women and Children's Hospital, Xi'an, Shaanxi 710061; \\ ${ }^{3}$ Department of Obstetrics and Gynecology, Renmin Hospital, Hubei University of Medicine, Shiyan, Hubei 442000, P.R. China
}

Received April 19, 2016; Accepted May 11, 2017

DOI: $10.3892 / \mathrm{etm} .2017 .5229$

\begin{abstract}
Human wings apart-like (hWAPL) is reported to have an association with cervical cancer. In the present study, the role of hWAPL in cervical cancer stem cells (CCSCs) was evaluated. Cervical tumorspheres were generated from cervical cancer tissues cultured in stem cell medium, and the expression of hWAPL by the tumorspheres was detected using immunohistochemistry. hWAPL expression levels in the tumorspheres were then upregulated using hWAPL adenoviral vectors or downregulated via the TAT-mediated knockdown of hWAPL and the effects on the tumorspheres were evaluated using colony formation, cell invasion and western blotting assays. The results demonstrated that the expression of hWAPL and human papillomavirus (HPV) was associated with the pluripotency of CCSCs, with hWAPL expression decreasing following the differentiation of cervical tumorspheres. Knockdown of hWAPL expression decreased HPV E6 expression and inhibited tumor invasion and colony formation. TAT-mediated knockdown of hWAPL with short interfering RNA significantly reduced tumor growth in nude mice. These results suggest that hWAPL is a marker of CCSC proliferation and is potentially a therapeutic target for cervical carcinoma through the downregulation of HPV E6.
\end{abstract}

\section{Introduction}

Cervical cancer is one of most common cancers in females and the second most common cause of cancer-related mortality in women in China; its mortality varies among provinces, with the highest mortality rates ranging from 7.28 to $11.88 / 10,000$ females

Correspondence to: Dr Zhao Duan, Department of Obstetrics and Gynecology, The Second Affiliated Hospital of Xi'an Jiaotong University, 157 Xiwu Road, Xi'an, Shaanxi 710004, P.R. China E-mail:zduan09@sina.com

*Contributed equally

Key words: human wings apart-like, proliferation, cervical cancer stem cells, human papillomavirus E6 in poorly developed areas (1). The poor prognosis of cervical cancer (including renal failure and metastasis) is associated with its highly invasive and diffusely metastatic characteristics $(2,3)$. Human papillomavirus (HPV) has been recognized to cause cervical carcinogenesis (1). The mechanism by which HPV induces tumor formation is considered to involve the binding of the viral oncoproteins HPV E6 and E7 to the tumor suppressors p53 and retinoblastoma protein, respectively (4).

Cervical cancer stem cells (CCSCs) are thought to be the 'seed cells' in cancer metastasis and recurrence (5-9). A number of studies have shown that CCSCs and core stem cell transcription factors (TFs) such as forkhead box D3 (5), sex-determining region Y-box 9 protein (Sox9) (6), Sox2 (7,8), Nanog (9) and octamer-binding protein 4 (Oct4) (8) are highly expressed in cervical cancer. These TFs are recognized as stem cell markers because they maintain the pluripotency of stem cells $(10,11)$. Recently, Tyagi et al (12) reported that HPV E6 is overexpressed in CCSCs, indicating that it plays a role in maintaining the pluripotency of these cells.

The human wings apart-like (hWAPL) gene is a homologous sequence of the Drosophila WAPL gene, and is closely associated with cervical carcinogenesis (13). HPV E6 and E7 are able to induce high levels of hWAPL expression, which plays a key role during the development of cervical cancer (14). Therefore, in the present study, the expression of hWAPL in CCSCs was evaluated, and its effects on invasion and colony formation in this cell population were investigated.

\section{Materials and methods}

Culture of tumorspheres derived from CCSCs. The study protocol was approved by the Medical Ethics Committees of Xi'an Jiaotong University (no. H34-32-1; Xi'an, China). All experiments were conducted in accordance with the Declaration of Helsinki. The method of culturing tumorspheres derived from CCSCs was conducted as previously reported (15). Briefly, 17 samples of cervical cancer tissue (stage IB, $n=11$; stage IC, $n=3$; stage IIa, $n=3$; patient age, 43-65 years) were obtained by resection. These samples were positive for HPV E6 expression, as determined by western blot analysis. To prepare the cervical tumorspheres (CTs), tumor tissues were washed immediately with PBS and digested overnight in Dulbecco's modified Eagle's medium(DMEM)/F12; v/v, 1:1; Gibco; Thermo Fisher Scientific, 
Inc., Waltham, MA, USA) supplemented with $0.5 \mathrm{mg} / \mathrm{ml}$ collagenase IV (Gibco; Thermo Fisher Scientific, Inc.). The digested tissues were then cultured in stem cell medium [DMEM/F12 with $10 \mathrm{ng} / \mathrm{ml}$ basic fibroblast growth factor (bFGF), $10 \mathrm{U} / \mathrm{ml}$ leukemia inhibitory factor, $1 \times 10^{5} \mathrm{U} / 1$ penicillin and $100 \mathrm{mg} / \mathrm{l}$ streptomycin; all from Merck KGaA, Darmstadt, Germany] at $37^{\circ} \mathrm{C}$ in a humidified atmosphere containing $5 \% \mathrm{CO}_{2}$. Clones of $>50$ cells were recognized as tumorspheres, and were dissociated every 7-10 days by incubation in a non-enzymatic cell dissociation solution (Sigma-Aldrich; Merck KGaA) for 2 min at $37^{\circ} \mathrm{C}$, and passaged at a density of $1 \times 10^{3}$ cells $/ 100-\mathrm{mm}$ plate. CTs were completely differentiated by 8 days after switching to stem cell medium without bFGF.

Transduction with adenoviral vectors. All adenoviral vectors (Ad5 serotype, E1/E3 deficiency double DNA; constructed by Beijing Nuosai Genome Research Center Co., Ltd., Beijing, China) used had comparable titers of $10^{8}-10^{9}$ transducing $\mathrm{U} / \mathrm{ml}$. Suspensions of the vectors were stored at $-80^{\circ} \mathrm{C}$ until use. The primers used for hWAPL overexpression are shown in Table I. Suspensions were briefly centrifuged (500 x g, room temperature) and kept on ice immediately prior to use. For transduction, $2 \times 10^{4}$ dissociated tumorspheres were transduced 1 day after the initial seeding of cells with a multiplicity of infection of 25 . Cells were incubated in stem cell medium containing adenoviral particles and $4 \mu \mathrm{g} / \mathrm{ml}$ Polybrene (Santa Cruz Biotechnology, Inc., Dallas, TX, USA) for $18 \mathrm{~h}$ at $37^{\circ} \mathrm{C}$ in a humidified atmosphere containing $5 \% \mathrm{CO}_{2}$. Adenoviral particles were removed, and the medium was replaced with fresh stem cell medium.

Colony formation assay. A colony formation assay was performed as previously described (15). Briefly, single cervical carcinoma cells or dissociated tumorspheres were cultured in DMEM/F-12 medium supplemented with $10 \%$ fetal calf serum (FCS; Thermo Fisher Scientific, Inc.), 2 mmol/l glutamine (Invitrogen; Thermo Fisher Scientific, Inc.), 1x10 $10^{5} \mathrm{U} / 1$ penicillin and $100 \mathrm{mg} / \mathrm{l}$ streptomycin. Cells were cultured at clonal densities of $100-300 / \mathrm{cm}^{2}$ on $2 \%$ gelatin (Sigma-Aldrich; Merck KGaA)-coated tissue culture dishes (BD Biosciences, San Jose, CA, USA) at $37^{\circ} \mathrm{C}$ in $5 \% \mathrm{CO}_{2}$ in air. Clones were monitored every day, and the medium was changed every 2-3 days. After 28 days of culture, plates were fixed in $10 \%$ formaldehyde/PBS for $10 \mathrm{~min}$ and stained with Harris hematoxylin. Clones ( $>50$ cells) were counted for $\geq 3$ plates per sample and averaged. The efficiency of colony formation was determined as follows: Efficiency $(\%)=$ number of colonies/number of cells seeded x 100 .

Implantation of tumorsphere-derived cells into nude mice. Following the dissociation of tumorspheres from 17 cervical cancer patients in a non-enzymatic cell-dissociation solution, cells were washed in serum-free Hank's balanced salt solution. Cells were then suspended in a 1:1 (v/v) mixture of serum-free $\mathrm{DMEM} / \mathrm{F} 12$, and $1 \times 10^{5}$ cells were injected subcutaneously into the right and left sides of the mid-abdominal area of nude mice using a 23-G needle. Animals were subjected to dissection and analysis 28 days after implantation, and tumor growth was assessed by measurement of the tumor volume (V) using the formula: $\mathrm{V}=1 / 2 \times\left(\mathrm{L} \times \mathrm{W}^{2}\right)$, where $\mathrm{L}$ is the length of the tumor and $\mathrm{W}$ is the width.
Western blotting. To extract the total protein, $1 \times 10^{4}$ cells were lysed in lysis buffer [1.0 M Tris- $\mathrm{HCl}(\mathrm{pH} 6.8) 1.0 \mathrm{ml}, 10 \%$ SDS $6.0 \mathrm{ml}, \beta$-mercaptoethanol $0.2 \mathrm{ml}$ and $\mathrm{ddH}_{2} \mathrm{O} 2.8 \mathrm{ml}$ ] on ice for $10 \mathrm{~min}$. The lysate was then subjected to centrifugation at $10,000 \mathrm{x} \mathrm{g}$ at $4^{\circ} \mathrm{C}$ for $10 \mathrm{~min}$. Following protein denaturation at $100^{\circ} \mathrm{C}$ for $10 \mathrm{~min}$, the protein level was normalized by measuring the absorbance at $280 \mathrm{~nm}$. Then, $80 \mu \mathrm{g}$ protein samples were analyzed by $12.5 \%$ SDS-PAGE and gels were transferred onto an Immobilon-P transfer membrane (polyvinylidene difluoride; EMD Millipore, Billerica, MA, USA). The membrane was blocked with $5 \%$ non-fat dried milk in TBST (10 mM Tris- $\mathrm{HCl}, 150 \mathrm{mM} \mathrm{NaCl}$ and $0.1 \%$ Tween-20) for $1 \mathrm{~h}$ at room temperature, and incubated overnight at $4^{\circ} \mathrm{C}$ with anti-HPV E6, Oct4 and hWAPL antibodies (1:100 dilution in PBS, cat. nos. sc-460, sc-101534 and sc-365189, respectively) or GAPDH (1:500 dilution, cat. no. sc-293335) (both from Santa Cruz Biotechnology, Inc.). Following incubation with horseradish peroxidase (HRP)-labeled rabbit anti-mouse secondary antibodies (1:2,000 dilution, cat. no. sc-358919; Santa Cruz Biotechnology, Inc.), membranes were developed using a SuperSignal ${ }^{\circledR}$ West Pico Trial kit (Pierce; Thermo Fisher Scientific, Inc.). Protein quantitation was conducted from the optical density using software for Bio-Rad's Molecular Imager ${ }^{\circledR}$ systems (Image Lab ${ }^{\text {TM }} 2.0$ and Molecular Imager ${ }^{\circledR}$ Gel Doc ${ }^{\mathrm{TM}}$ XR System; Bio-Rad Laboratories, Inc., Hercules, CA, USA). All experiments were repeated three times.

Immunohistochemical analysis. Cervical cancer samples were fixed in phosphate-buffered $10 \%$ formalin ( $\mathrm{pH} 7.2$ ), embedded in paraffin and cut into $4-\mu \mathrm{m}$ sections. The sections were dewaxed in xylene, dehydrated in alcohol, and then incubated in $0.01 \mathrm{M}$ sodium citrate buffer $(\mathrm{pH} \mathrm{6.0)}$ ) for antigen retrieval. Sections were incubated with $3 \% \mathrm{H}_{2} \mathrm{O}_{2}$ for 30 min to block endogenous peroxidase activity, and with $10 \%$ milk at $37^{\circ} \mathrm{C}$ for 15 min to block non-specific binding of antibodies. Sections were then incubated with hWAPL, Oct4 or HPV E6 antibodies (1:100 dilution in PBS, cat. nos. sc-365189, sc-101534 and sc-460, respectively; Santa Cruz Biotechnology, Inc.) for $2 \mathrm{~h}$ at room temperature. This was followed by incubation with biotinylated secondary antibody (1:2,000, cat. no. sc-358919; Santa Cruz Biotechnology, Inc.) at room temperature for $1 \mathrm{~h}$ and visualization using 3,3'-diaminobenzidine under a light microscope.

Injection of transactivating transcriptional factor (TAT)-mediated si-hWAPL or si-HPV E6 into tumorspheres or exograft tumors in nude mice. Synthesis of TAT was performed as described in a previous study (16). In brief, $50 \mathrm{nM}$ siRNAs (Ambion; Thermo Fisher Scientific, Inc.) were dissolved in RNase-free $\mathrm{ddH}_{2} \mathrm{O}$ and then mixed with $10 \mu \mathrm{M}$ TAT at a TAT:siRNA molar ratio of 20:1 and incubated for $30 \mathrm{~min}$ at $37^{\circ} \mathrm{C}$. The siRNA sequences are shown in Table II. For in vivo use, treatment of the tumors was initiated at 2 weeks after tumorsphere implantation, as previously described (17). In brief, dissociated cells from tumorspheres were injected into the left and right sides of the mouse (as described above), and palpable tumors were formed 2 weeks later. At this time point, the tumor site on one side of the mouse was injected with TAT-mediated si-hWAPL (100 $\mu \mathrm{M}$ TAT/siRNA) and that 
Table I. Primers for overexpression of hWAPL.

\begin{tabular}{lll}
\hline Gene & Primer & \multicolumn{1}{c}{ Sequence } \\
\hline hWAPL & Sense & 5'-TTAAGCTTTGAAACTGGTGTCAAAATGACATCCAGATT-3' \\
& Antisense & 5'-TTGAATTCAAGCAATGTTCCAAATATTCAATCACTCTAGAG-3' \\
GAPDH & Sense & 5'-AAGGCTGAGAATGGGAAAC-3' \\
& Antisense & 5'-TTCAGGGACTTGTCATACTTC-3'
\end{tabular}

hWAPL, human wings apart-like.

Table II. siRNA sequences.

\begin{tabular}{lll}
\hline siRNA & Primer & \multicolumn{1}{c}{ Sequence $\left(5^{\prime}-3^{\prime}\right)$} \\
\hline Si-hWAPL 1 & Sense & ACAGUUUUUAUCACUUUGGAU \\
& Antisense & CCAAAGUGAUAAAAACUGUGA \\
Antisense & CCAGAUUUGGGAAAACAUACA \\
Si-HPV E6 1 & Sense & GCAACAGUUACUGCGACGUUU \\
& Antisense & ACGUCUCGCAGUAACUGUUGCUU \\
Antisense & AGCUGGGUUUCUCUACGUGUU \\
& Sense & GACCUGUUAAUGACGGCACUU \\
GAPDH & Antisense & GUGCCGUCAUUAACAGGUCUU \\
& Sense & AAGGCTGAGAATGGGAAAC \\
& Antisense & TTCAGGGACTTGTCATACTTC
\end{tabular}

siRNA, short interfering RNA; hWAPL, human wings apart-like; HPV, human papillomavirus.

on the other side was injected with control [scrambled (Scr) siRNA]. The tumor size was measured each week.

Cell invasion assay. Cell invasion was evaluated using 24-well Transwell ${ }^{\circledR}$ culture chambers, as previously described (17). Cells dissociated from tumorspheres were seeded at a density of $5 \times 10^{4}$ cells per well and cultured in stem cell medium (as mentioned above) containing $2 \%$ fetal bovine serum (cat. no. 10082139; Thermo Fisher Scientific, Inc.) for $24 \mathrm{~h}$ at $37^{\circ} \mathrm{C}$ in a humidified atmosphere containing $5 \% \mathrm{CO}_{2}$. Cells in the lower compartment were then fixed in methanol and stained with $5 \%$ crystal violet for $10 \mathrm{~min}$ at room temperature. The cells were counted under a light microscope. Three fields per sample were examined.

Statistical analysis. Data are shown as the mean \pm standard error of the mean. Comparisons of the groups were performed using analysis of variance, Fisher's exact test or two-tailed Student's t-test. $\mathrm{P}<0.05$ was considered to indicate a statistically significant difference.

\section{Results}

Expression of $h W A P L$ and core stem cell TFs in undifferentiated CCSCs. All cervical cancer tissue specimens from the patients tested positive for HPV E6 expression, and the majority (15/17) were immunopositive for hWAPL (Fig. 1A).
A

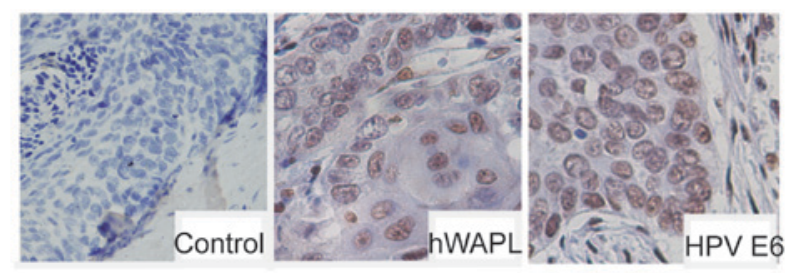

B

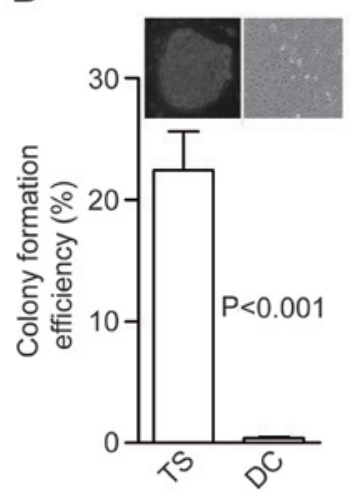

C

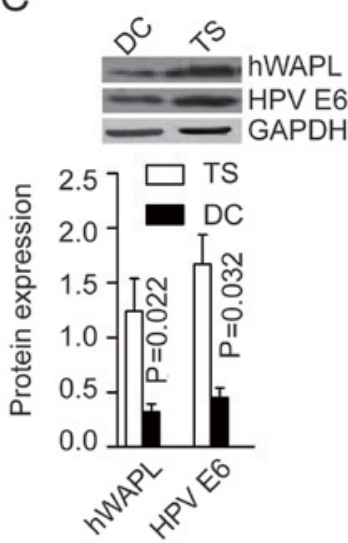

Figure 1. hWAPL expression in TS or DC. (A) In situ expression of hWAPL and HPV E6 in cervical carcinoma samples (magnification, $x 400$ ). (B) Colony formation of cells dissociated from TS or DC $(n=3)$. (C) Expression of hWAPL and HPV E6 in cells dissociated from TS or DC. GAPDH was used as the loading control. hWAPL, human wings apart-like; TS, tumorspheres; DC, differentiated cells; HPV, human papillomavirus. 

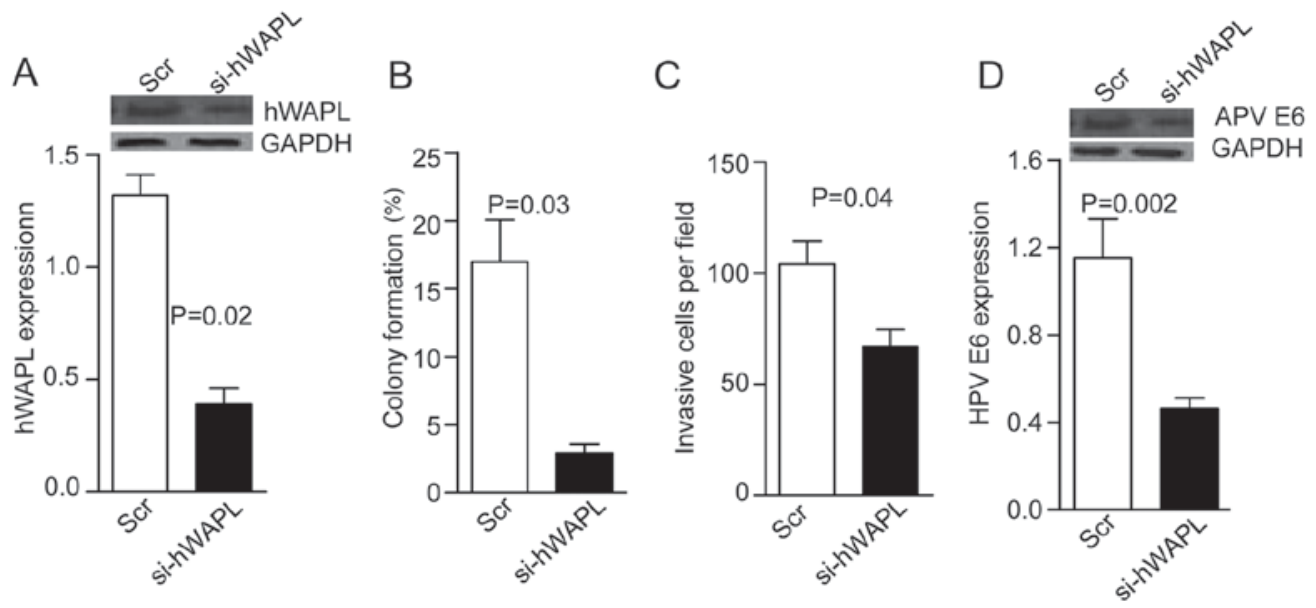

Figure 2. Knockdown of hWAPL induces tumorsphere differentiation and inhibits tumorsphere invasion and colony formation. (A) hWAPL expression, (B) colony formation, (C) invasion and (D) HPV E6 expression all decreased following hWAPL downregulation using si-hWAPL (n=3). hWAPL, human wings apart-like; HPV, human papillomavirus; si-hWAPL, short interfering RNA against hWAPL; Scr, scrambled control.
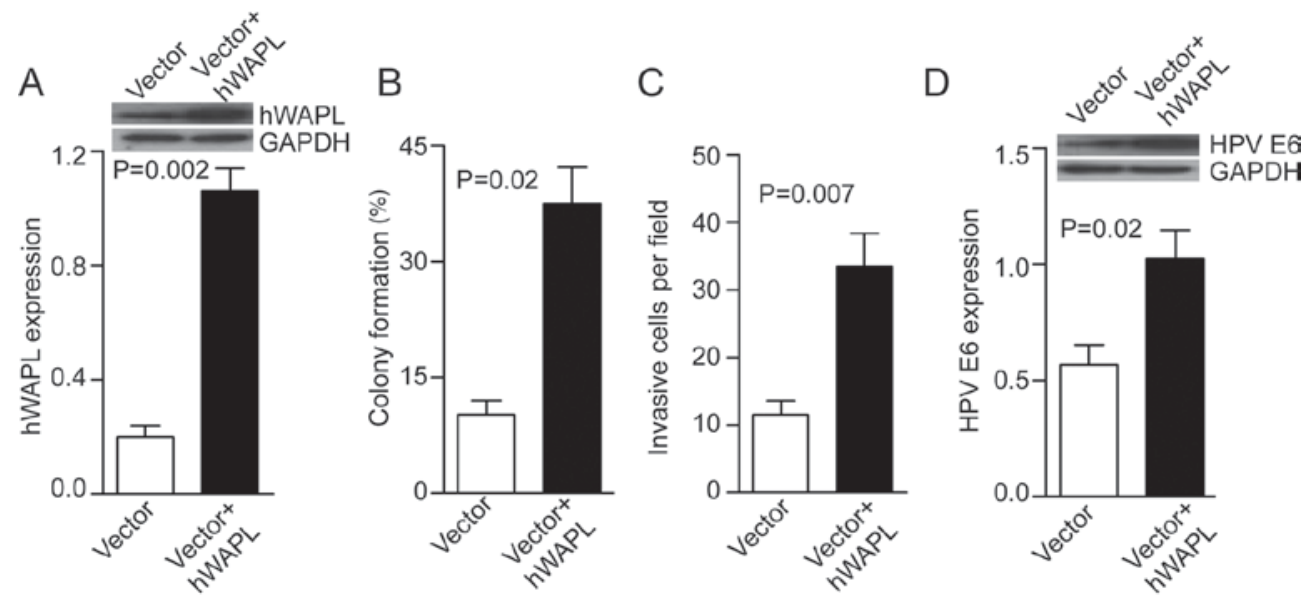

Figure 3. Overexpression of hWAPL maintains pluripotency and increases tumorsphere invasion and tumor formation. (A) hWAPL expression, (B) colony formation, (C) invasion and (D) HPV E6 expression all increased following the overexpression of hWAPL ( $\mathrm{n}=3$ ). hWAPL, human wings apart-like; HPV, human papillomavirus.

Following enzymatic dissociation and culture in stem cell medium, a few colonies (tumorspheres) formed in all of the tissues tested (17/17) after 2 weeks. Colonies were formed at the rate of $21.53 \pm 2.64 \%$ for cells dissociated from tumorspheres, and only $0.41 \pm 0.07 \%$ for cells dissociated from differentiated tumorspheres $(\mathrm{P}<0.001$; Fig. $1 \mathrm{~B})$. In addition, protein levels of hWAPL $(\mathrm{P}=0.022)$ and HPV E6 $(\mathrm{P}=0.032)$ were significantly higher in tumorspheres than in differentiated cells (Fig. 1C).

Knockdown of hWAPL induces tumorsphere differentiation and HPV E6 downregulation. The role of hWAPL in cervical cancer was investigated. TAT-mediated si-hWAPL was co-cultured with tumorspheres for $30 \mathrm{~min}$. After $24 \mathrm{~h}$, western blot analyses showed that hWAPL levels decreased by $\sim 3$-fold in the si-hWAPL group compared with the controls $(\mathrm{P}=0.02$; Fig. 2A). Notably, in addition to decreased tumorsphere formation ( $\mathrm{P}=0.03$; Fig. $2 \mathrm{~B}$ ) and invasion ( $\mathrm{P}=0.04$; Fig. $2 \mathrm{C})$, HPV E6 expression also decreased following the knockdown of hWAPL ( $\mathrm{P}=0.002$; Fig. 2D).
Overexpression of hWAPL promotes tumorsphere tumorigenicity by increasing HPV E6 expression. Next, the tumorspheres were transfected with either Ad-hWAPL (Ad-hWAPL-GFP) vector for overexpression of hWAPL, or its control (Ad-scr-GFP). In the Ad-hWAPL transfected tumorspheres, hWAPL expression levels were increased 4-fold compared with those in the control $(\mathrm{P}=0.002$; Fig. 3A), colony formation ( $\mathrm{P}=0.02$; Fig. 3B) and cell invasion $(\mathrm{P}=0.007$; Fig. 3C) were also increased. HPV E6 expression also increased following hWAPL overexpression ( $\mathrm{P}=0.023$; Fig. 3D).

Knockdown of HPV E6 inhibits the invasion and colony formation of CTs. Following the coculture of TAT-mediated si-HPV E6 with tumorspheres for $30 \mathrm{~min}$, the levels of HPV E6 were decreased $~ 4$-fold in the si-HPV E6 group compared with the control group ( $\mathrm{P}=0.021$; Fig. 4A). HPV E6 knockdown inhibited hWAPL expression ( $\mathrm{P}=0.024$; Fig. 4B), and also reduced colony formation $(\mathrm{P}=0.023$; Fig. $4 \mathrm{C})$ and cell invasion $(\mathrm{P}=0.032$; Fig. 4D) compared with that of control CTs. 

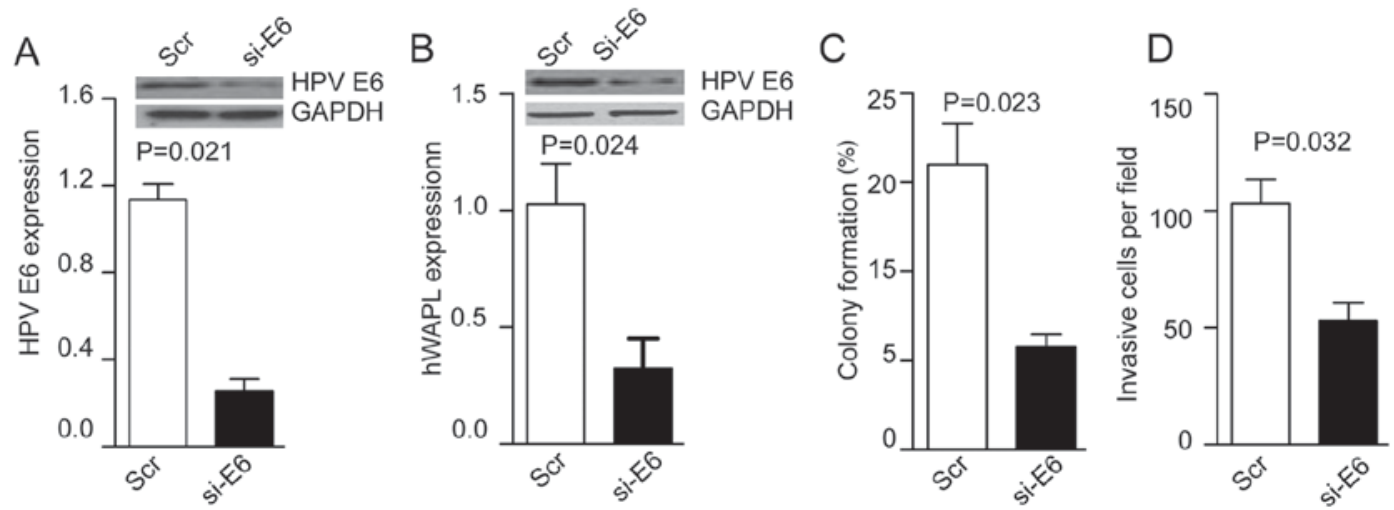

Figure 4. Knockdown of HPV E6 reduces hWAPL expression, colony formation and invasion in tumorspheres. (A) HPV E6 expression, (B) hWAPL expression, (C) colony formation and (D) invasion decreased in tumorspheres following HPV E6 knockdown using si-E6 (n=3). hWAPL, human wings apart-like; HPV, human papillomavirus; si-E6, short interfering RNA against HPV E6; Scr, scrambled control.
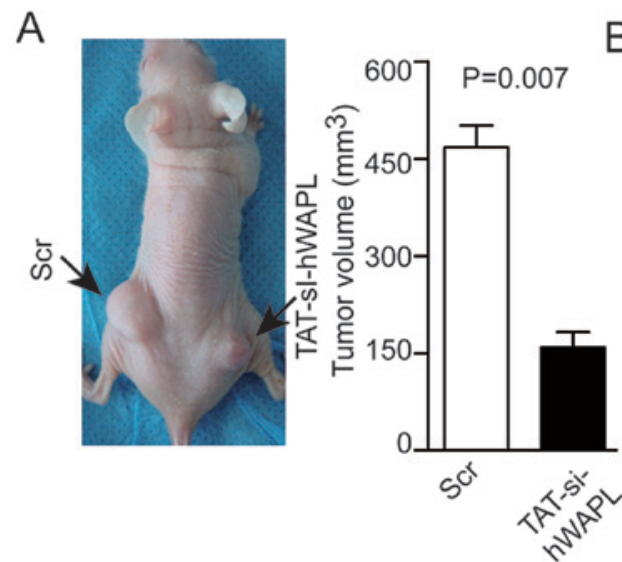

$\mathrm{B}$
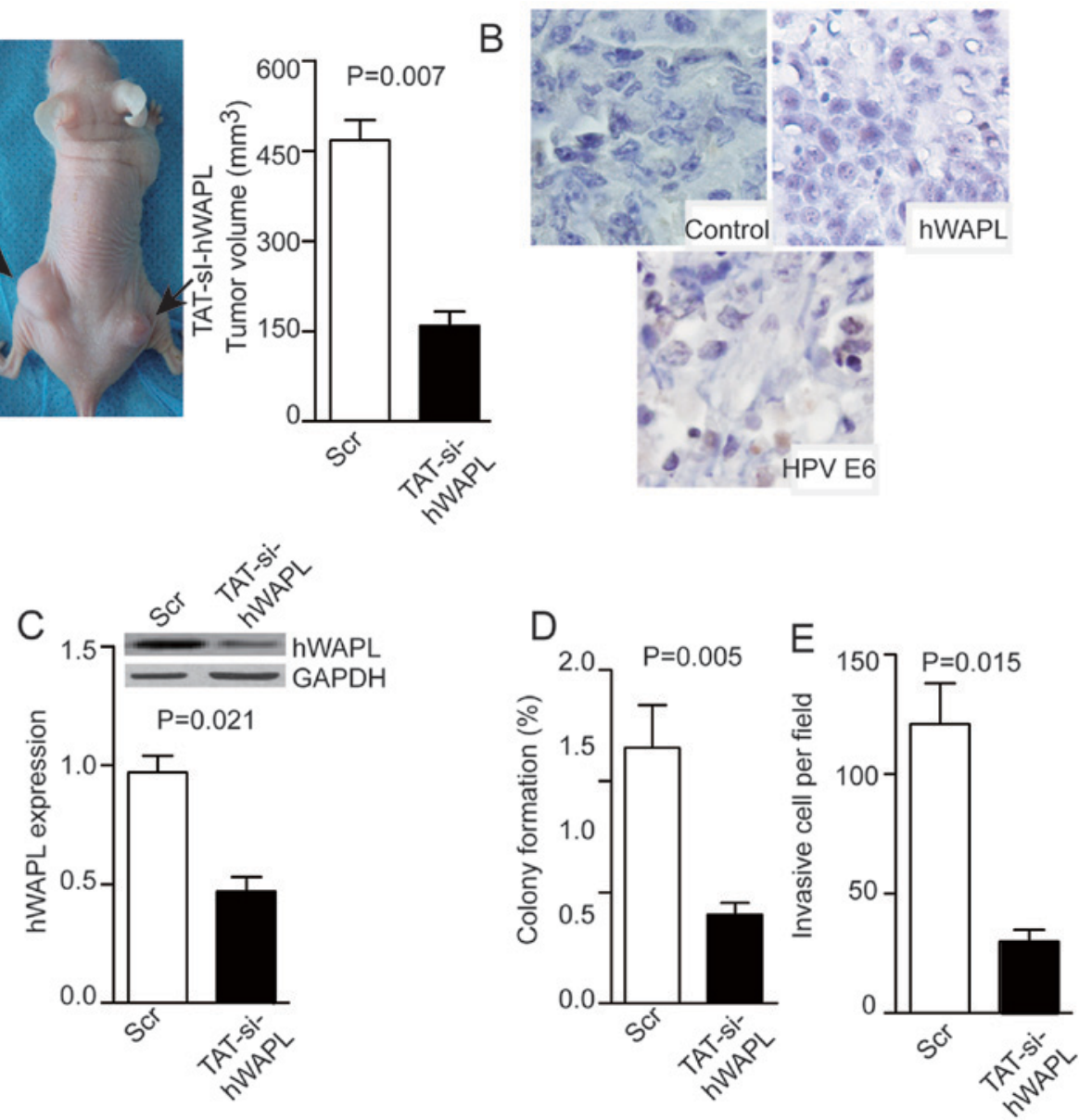

Figure 5. Injection of TAT-si-hWAPL into transplanted tumors inhibits tumor growth, hWAPL expression, colony formation, and tumorsphere invasion. (A) Injection of TAT-si-hWAPL into transplanted tumors inhibited tumor growth, (B) suppressed the expression of hWAPL and HPV E6 as shown by immunohistochemistry (magnification, $\mathrm{x} 400$ ), (C) decreased hWAPL expression as detected by western blot analysis and decreased (D) colony formation and (E) cell invasion ( $\mathrm{n}=3$ ). hWAPL, human wings apart-like; HPV, human papillomavirus; TAT-si-hWAPL, TAT-mediated short interfering RNA against hWAPL; Scr, scrambled control.

TAT-mediated si-hWAPL inhibits the growth of tumors derived from CTs. Tumor cells were dissociated from tumorspheres and injected into null mice. The resulting tumors were visible or palpable 2 weeks after injection. Subsequently, $100 \mu \mathrm{M} / \mathrm{mg}$ TAT/siRNA or its control (Scr) were injected into tumors once per week. Mice were sacrificed at day 28 and the tumor volume was measured. Tumors in the TAT-mediated si-hWAPL group were smaller compared with those in the Scr group $(\mathrm{P}=0.007$; Fig. 5A), and the weak expression of hWAPL and HPV E6 was detected after si-hWAPL treatment (Fig. 5B). The expression of hWAPL was decreased in the si-hWAPL group compared with that in the control group, as determined 
by western blotting $(\mathrm{P}=0.021$; Fig. $5 \mathrm{C})$. Moreover, in the si-hWAPL group compared with the control group, colony formation $(\mathrm{P}=0.005$; Fig. 5D) and cell invasion $(\mathrm{P}=0.015$; Fig. 5E) was decreased.

\section{Discussion}

Cervical cancer is caused by HPV infection (18). The HPV E6 oncoprotein induces proteasome-dependent p53 degradation and inhibits expression of the $\mathrm{p} 53$ tumor suppressor protein. The HPV E6 protein targets the cellular E3 ubiquitin ligase E6AP to p53, resulting in the transfer of ubiquitin peptides from E6AP to p53, which induces degradation of p53 by the $26 \mathrm{~S}$ proteasome (19). Knockdown of HPV E6 has been shown to efficiently kill HPV-positive cancer cells (20). In addition, it has been reported that HPV E6 is selectively overexpressed in CCSCs, and that the silencing of HPV E6 using siRNA abolishes CT formation and induces tumorsphere re-differentiation (21). In the present study, it was observed that HPV E6 was expressed in all the cervical cancer samples tested, indicating that it plays an important role in the maintenance of CCSC proliferation.

The WAPL gene was first identified in fruit flies $(22,23)$. The human WAPL (hWAPL) gene is homologous in sequence to WAPL, is 30,793 base pairs in length, and is located on chromosome 10q23.2. The hWAPL gene encodes an aggregated anchored protein that disaggregates the polymerization of chromosome arms in the early stage of mitosis (24). The hWAPL protein is highly expressed in cervical cancer patients, and HPV E6 and E7 oncoproteins induce hWAPL expression (25). Moreover, HPV E6 is associated with cervical carcinogenesis, and as such, is a therapeutic target for cervical cancer (26). Nevertheless, little is known about the function of hWAPL in cervical cancer. The results of the present study indicate the potential of hWAPL as a marker of CCSC proliferation and suggest that hWAPL may play a role in maintaining the proliferation potential of CCSCs. It has previously been reported that HPV E6 induces hWAPL expression (25). In the present study, it was found that hWAPL has a counteractive effect on HPV E6 expression, indicating that HPV E6 and hWAPL interact in cervical carcinogenesis.

Cell-penetrating peptides (CPPs), which are short cationic polypeptides comprising $\leq 30$ amino acids, have been used for the intracellular delivery of various macromolecules (27). TAT and MPG proteins from HIV-1, as well as penetratin and polyarginine, have been used as CPPs to facilitate the intracellular delivery of proteins and nucleic acids (28). TAT-CPPs enabled the safe and effective delivery of siRNAs for the knockdown of hWAPL in CCSCs to inhibit CCSC invasion and proliferation in the present study. In a previous study, Zhang et al (29) constructed a peptide that was able to deliver si-hWAPL to HeLa cervical cancer cells and successfully reduced hWAPL expression in those cells. As an extension of that previous study, the present study indicated that hWAPL interacts with HPV E6 and may be a marker of CCSC proliferation. Notably, the knockdown of hWAPL reduced cervical cancer proliferation, metastasis and recurrence. However, the present study has certain limitations. The experiments were only performed in mice, and should be repeated in higher level species. In addition, immune maintenance and whether the local injection has any effect on other organs requires investigation in future studies.

\section{Acknowledgements}

This study was supported by the Natural Science Foundation of Shanxi Province, China (grant no. 2013JM4012) and Natural Science Foundation of Shiyan (grant no. 15Y38).

\section{References}

1. Li J, Kang LN and Qiao YL: Review of the cervical cancer disease burden in mainland China. Asian Pac J Cancer Prev 12: 1149-1153, 2011.

2. Shepherd JH: Cervical cancer. Best Pract Res Clin Obstet Gynaecol 26: 293-309, 2012.

3. Shi JF, Canfell K, Lew JB and Qiao YL: The burden of cervical cancer in China: Synthesis of the evidence. Int J Cancer 130: 641-652, 2012.

4. Yim EK and Park JS: The role of HPV E6 and E7 oncoproteins in HPV-associated cervical carcinogenesis. Cancer Res Treat 37: 319-324, 2005.

5. Li D, Mei H, Qi M, Yang D, Zhao X, Xiang X, Pu J, Huang K, Zheng L and Tong Q: FOXD3 is a novel tumor suppressor that affects growth, invasion, metastasis and angiogenesis of neuroblastoma. Oncotarget 4: 2021-2044, 2013.

6. Wang HY, Lian P and Zheng PS: SOX9, a potential tumor suppressor in cervical cancer, transactivates $\mathrm{p} 21^{\mathrm{WAF} 1 / \mathrm{CIP} 1}$ and suppresses cervical tumor growth. Oncotarget 6: 20711-20722, 2015.

7. Shen L, Huang X, Xie X, Su J, Yuan J and Chen X: High expression of SOX 2 and OCT4 indicates radiation resistance and an independent negative prognosis in cervical squamous cell carcinoma. J Histochem Cytochem 62: 499-509, 2014.

8. Ji J, Wei X and Wang Y: Embryonic stem cell markers Sox-2 and OCT4 expression and their correlation with WNT signal pathway in cervical squamous cell carcinoma. Int J Clin Exp Pathol 7: 2470-2476, 2014

9. Ding Y, Yu AQ, Li CL, Fang J, Zeng Y and Li DS: TALEN-mediated Nanog disruption results in less invasiveness, more chemosensitivity and reversal of EMT in HeLa cells. Oncotarget 5: 8393-8401, 2014.

10. Wang ML, Chiou SH and Wu CW: Targeting cancer stem cells: Emerging role of Nanog transcription factor. Onco Targets Ther 6: 1207-1220, 2013.

11. Pei D: Regulation of pluripotency and reprogramming by transcription factors. J Biol Chem 284: 3365-3369, 2009.

12. Tyagi A, Vishnoi K, Mahata S, Verma G, Srivastava Y, Masaldan S, Roy BG, Bharti AC and Das BC: Cervical cancer stem cells selectively overexpress HPV oncoprotein E6 that controls stemness and self renewal through upregulation of HES1. Clin Cancer Res 22: 4170-4184, 2016.

13. Oikawa K, Ohbayashi T, Kiyono T, Nishi H, Isaka K, Umezawa A, Kuroda M and Mukai K: Expression of a novel human gene, human wings apart-like (hWAPL), is associated with cervical carcinogenesis and tumor progression. Cancer Res 64: 3545-3549, 2004.

14. Oikawa K, Akiyoshi A, Tanaka M, Takanashi M, Nishi H, Isaka K, Kiseki H, Idei T, Tsukahara Y, Hashimura N, et al: Expression of various types of alternatively spliced WAPL transcripts in human cervical epithelia. Gene 423: 57-62, 2008.

15. Zhou X, Gao Q, Wang J, Zhang X, Liu K and Duan Z: Linc-RNA-RoR acts as a 'sponge' against mediation of the differentiation of endometrial cancer stem cells by microRNA-145. Gynecol Oncol 133: 333-339, 2014.

16. Lee JY, Choi YS, Suh JS, Kwon YM, Yang VC, Lee SJ, Chung CP and Park YJ: Cell-penetrating chitosan/doxorubicin/TAT conjugates for efficient cancer therapy. Int J Cancer 128: 2470-2480, 2011.

17. Liu Y, Lv L, Xiao W, Gong C, Yin J, Wang D and Sheng H: Leptin activates STAT3 and ERK1/2 pathways and induces endometrial cancer cell proliferation. J Huazhong Univ Sci Technolog Med Sci 31: 365-370, 2011.

18. Crosbie EJ, Einstein MH, Franceschi S and Kitchener HC: Human papillomavirus and cervical cancer. Lancet 382: 889-899, 2013.

19. Beaudenon S and Huibregtse JM: HPV E6, E6AP and cervical cancer. BMC Biochem 9 (Suppl 1): S4, 2008. 
20. Butz K, Ristriani T, Hengstermann A, Denk C, Scheffner M and Hoppe-Seyler F: siRNA targeting of the viral E6 oncogene efficiently kills human papillomavirus-positive cancer cells. Oncogene 22: 5938-5945, 2003.

21. Tyagi A, Vishnoi K, Mahata S, Verma G, Srivastava Y, Masaldan S, Roy BG, Bharti AC and Das BC: Cervical cancer stem cells selectively overexpress HPV oncoprotein E6 that controls stemness and self-renewal through upregulation of HES1. Clin Cancer Res 22: 4170-4184, 2016.

22. Verni F, Gandhi R, Goldberg ML and Gatti M: Genetic and molecular analysis of wings apart-like (wapl), a gene controlling heterochromatin organization in Drosophila melanogaster. Genetics 154: 1693-1710, 2000.

23. Dobie KW, Kennedy CD, Velasco VM, McGrath TL, Weko J, Patterson RW and Karpen GH: Identification of chromosome inheritance modifiers in Drosophila melanogaster. Genetics 157: $1623-1637,2001$.

24. Kueng S, Hegemann B, Peters BH, Lipp JJ, Schleiffer A, Mechtler K and Peters JM: Wapl controls the dynamic association of cohesin with chromatin. Cell 127: 955-967, 2006.
25. Kuroda M, Kiyono T, Oikawa K, Yoshida K and Mukai K: The human papillomavirus E6 and E7 inducible oncogene, hWAPL, exhibits potential as a therapeutic target. Br J Cancer 92: 290-293, 2005.

26. Wang W, Abbad S, Zhang Z, Wang S, Zhou J and Lv H: Cell-penetrating peptides for cancer-targeting therapy and imaging. Curr Cancer Drug Targets 15: 337-351, 2015.

27. Heitz F, Morris MC and Divita G: Twenty years of cell-penetrating peptides: From molecular mechanisms to therapeutics. $\mathrm{Br}$ J Pharmacol 157: 195-206, 2009.

28. Munyendo WL, Lv H, Benza-Ingoula H, Baraza LD and Zhou J: Cell penetrating peptides in the delivery of biopharmaceuticals. Biomolecules 2: 187-202, 2012.

29. Zhang H, Mao Y, Zhang F, Ye C, Tong H, Su Y and Zhu J: The inhibitory effect of a new $\mathrm{scFv} / \mathrm{tP}$ protein as siRNA delivery system to target hWAPL in cervical carcinoma. Mol Cell Biochem 391: 77-84, 2014. 